\title{
Preparation of manganese-based perovskite nanoparticles using a reverse microemulsion method: biomedical applications
}

\author{
MEYSAM SOLEYMANI* and MOHAMMAD EDRISSI \\ Department of Chemical Engineering, Amirkabir University of Technology, Hafez Ave., 15875-4413 Tehran, Iran
}

MS received 8 July 2015; accepted 29 October 2015

\begin{abstract}
In this study, $\mathrm{La}_{0.7} \mathrm{Sr}_{0.3} \mathrm{Mn}_{0.98} \mathrm{Ti}_{0.02} \mathrm{O}_{3}$ (LSMTO) nanoparticles with a perovskite structure and an average particle size of $23.5 \mathrm{~nm}$ were synthesized using a reverse microemulsion method. In this method, cetyltrimethylammonium bromide (CTAB) was used as a surfactant, 1-butanol as a co-surfactant, $n$-hexane as a continuous oil phase, and an aqueous solution containing metal cations or precipitating agent as a dispersed aqueous phase. The aqueous nanodroplets of microemulsions were used for the formation of perovskite precursor. The obtained precursor was then calcined at $700^{\circ} \mathrm{C}$ for $4 \mathrm{~h}$ to convert the precursor to the perovskite phase. In addition, the heating ability of the LSMTO nanoparticles was evaluated under a safe alternating magnetic field used in magnetic hyperthermia therapy. The results showed the fast magneto-temperature response of the prepared sample with sufficient heat loss at the therapeutic temperature range, indicating the LSMTO nanoparticles can be used as a self-regulated heating agent in the magnetic hyperthermia therapy.
\end{abstract}

Keywords. Reverse microemulsion; hyperthermia; magnetic nanoparticles; heat generation.

\section{Introduction}

In recent years, magnetic nanoparticles (MNPs) have attracted much attention in various fields of medicine and pharmacology such as magnetically activated drug delivery systems [1,2], bio-separation [3], magnetic resonance imaging (MRI) [4] and magnetic hyperthermia therapy [5,6]. Gilchrist et al [7] was first presented the concept of magnetic hyperthermia in 1957. In this method, MNPs were introduced to a cancer tissue via direct injecting, magnetic or active/passive targeting approaches. Then the cancer tissue was irradiated by an alternating magnetic field (AMF), leading to heat generation by the ferromagnetic/superparamagnetic nanoparticles, which can destroy or damage the cancerous cells. In this method, the temperature of the cancer tissue is regulated at a Curie temperature $\left(T_{\mathrm{c}}\right)$ of the MNPs. Therefore the Curie temperature of the MNPs should be in the desired temperature range for hyperthermia therapy $\left(41-47^{\circ} \mathrm{C}\right)$ to prevent overheating of healthy tissues. Recently, ferromagnetic materials such as the series of $\mathrm{La}_{1-x} \mathrm{Sr}_{x} \mathrm{MnO}_{3}$ (LSMO) compounds with tunable $T_{\mathrm{c}}$ between 10 and $90^{\circ} \mathrm{C}$ for $0.18<x<$ 0.6 , have attracted great interest for hyperthermia application [8]. Phuc et al [9] showed that the replacement of Mn ions by titanium in $\mathrm{La}_{1-x} \mathrm{Sr}_{x} \mathrm{Mn}_{1-y} \mathrm{Ti}_{y} \mathrm{O}_{3}$ have particular advantages over the variation of $\mathrm{Sr}$ doping level for tuning the $T_{\mathrm{c}}$ of the component.

Several techniques have been employed for the synthesis of LSMO nanoparticles such as the sol-gel method [10], precipitation [11], sonochemical [12], thermal decomposition

\footnotetext{
*Author for correspondence (msol.chem.eng@aut.ac.ir)
}

[13] and ball mill method [14]. Reverse microemulsion method has been demonstrated as a versatile method to produce a variety of nanoparticles [15]. The method consists of aqueous nanodroplets stabilized by surfactant molecules in organic media. This method has advantages over other type of synthetic methods as it produces uniform, homogeneous and monodisperse nanosized precursors.

There are only few reports on the synthesis of LSMO nanoparticles via the reverse microemulsion method $[16,17]$. To our knowledge, there is no report available in the literature on the synthesis of $\mathrm{La}_{0.7} \mathrm{Sr}_{0.3} \mathrm{Mn}_{1-y} \mathrm{Ti}_{y} \mathrm{O}_{3}$ nanoparticles using the reverse microemulsion method and their application for magnetic hyperthermia. In this paper, the synthesis of $\mathrm{La}_{0.7} \mathrm{Sr}_{0.3} \mathrm{Mn}_{0.98} \mathrm{Ti}_{0.02} \mathrm{O}_{3}$ (LSMTO) nanoparticles by reverse microemulsion route was reported. The precursor and obtained nanoparticles were characterized by X-ray diffraction (XRD) analysis, thermogravimetric (TG) analysis and transmission electron microscopy (TEM). In addition, the heating efficacy of the obtained nanoparticles was evaluated by induction heating analysis.

\section{Materials and methods}

\subsection{Materials}

$\mathrm{La}\left(\mathrm{NO}_{3}\right)_{3} \cdot 6 \mathrm{H}_{2} \mathrm{O}$ (Sigma), $\mathrm{Mn}\left(\mathrm{NO}_{3}\right)_{2} \cdot 4 \mathrm{H}_{2} \mathrm{O}$ (Merck), $\mathrm{Sr}\left(\mathrm{NO}_{3}\right)_{3}$ (Merck), cetyltrimethylammonium bromide (CTAB, Merck), 1-butanol (Sigma), $n$-octane (Sigma) and $n$ hexane (Sigma) were purchased and used without further purification. 


\subsection{LSMTO nanoparticles synthesis}

For reverse microemulsion method two microemulsions (Mic-A and Mic-B) were prepared which consisted of CTAB as the surfactant, 1-butanol as the co-surfactant, $n$-octane as the continuous oil phase and an aqueous solution as the dispersed phase. The amount of each phase is indicated in table 1.

In the Mic-A the aqueous phase contained the metal nitrates and in the Mic-B the precipitating agent. The aqueous phase of metal nitrate had the concentrations of $0.07 \mathrm{M}$ La, 0.03 M Sr, 0.98 M Mn and $0.02 \mathrm{M} \mathrm{Ti}$ ions. The precipitating agent solution was ammonium oxalate in the concentration of $0.3 \mathrm{M}$. The two prepared microemulsions were mixed together and then the resulting solution was aged for $12 \mathrm{~h}$ at room temperature. Finally, the obtained precipitate (perovskite precursor) was separated by centrifugation and washed several times with ethanol and water to remove excess surfactants and other impurities. Finally, the obtained product was dried in an oven at $150^{\circ} \mathrm{C}$ overnight and then calcined at $700^{\circ} \mathrm{C}$ for $4 \mathrm{~h}$.

\subsection{Characterization}

The crystalline structure of the samples was determined by $\mathrm{X}$-ray powder diffraction (XRD) analysis at room temperature by a Philips X'Pert powder diffractometer with $\mathrm{Cu} \mathrm{K} \alpha$ radiation and $\mathrm{Ni}$ filter $(\lambda=0.15418 \mathrm{~nm})$. TEM (JEOL 1200 EX) was used to determine the size and shape of the synthesized nanoparticles. TG analysis curves were obtained using a Perkin-Elmer Diamond TG/DTA instrument.

Table 1. Amount of aqueous and organic phases in Mic-A and Mic-B.

\begin{tabular}{lccc}
\hline & Mic-A & Mic-B & Vol. (ml) \\
\hline Aqueous phase & Metal ions & Precipitating agent & 10 \\
Surfactant & CTAB & CTAB & 10 \\
Co-surfactant & 1-butanol & 1-butanol & 10 \\
Oil phase & $n$-Hexane & $n$-Hexane & 70 \\
\hline
\end{tabular}

\subsection{Induction heating analysis}

The heating efficacy of LSMTO nanoparticles was evaluated using a custom-made induction heating unit with five turns (5 cm diameter) induction coil. An aqueous suspension of nanoparticles $(1.5 \mathrm{ml})$ was placed in the center of induction coil and then irradiated by different magnetic fields ( $H=6$ and $10 \mathrm{kA} \mathrm{m}^{-1}, f=100 \mathrm{kHz}$ ). The temperature of the prepared sample was measured by an alcohol thermometer. Also, the heating efficacy of the synthesized nanoparticles was evaluated by calculating the specific absorption rate (SAR) of the sample as follows:

$$
\mathrm{SAR}=\left(\frac{C_{\text {suspension }}}{X_{\mathrm{NP}}}\right)\left(\frac{\mathrm{d} T}{\mathrm{~d} t}\right),
$$

where $C_{\text {suspension }}$ is the specific heat of suspension $\left[C_{\text {water }}=\right.$ $4.18 \mathrm{~J} \mathrm{~g}^{-1} \mathrm{k}^{-1}$ and $C_{\mathrm{NP}}=0.66 \mathrm{~J} \mathrm{~g}^{-1} \mathrm{k}^{-1}$ ] [17], $X_{\mathrm{NP}}$ the weight fraction of nanoparticles $\left(X_{\mathrm{NP}}=0.1\right)$ and $\mathrm{d} T / \mathrm{d} t$ the initial slope of the temperature curve $v s$. time.

\section{Results and discussion}

Reverse microemulsion method was performed using two microemulsions containing the metal nitrates and precipitating agent, respectively. Two microemulsions were mixed under gentle stirring which results in the frequent collision of the aqueous nanodroplets in microemulsion, leading to the formation of perovskite precursors in nanoreactors. The production of the hydroxid precursors is illustrated in figure 1. Final product was obtained by calcination of the obtained precursor at low temperature due to the homogeneous mixing of the metal ions and very small size of the primary precursor.

\subsection{TG analysis}

Figure 2 shows thermogravimetry diagram of the precursor obtained by the reverse microemulsion method. The first small weight loss about $5 \%$ below $180^{\circ} \mathrm{C}$ is related to the dehydration and loss of absorbed water. The major weight loss in the range of $200-400^{\circ} \mathrm{C}$ is attributed to decomposition of metal hydroxides and formation of LSMTO nanoparticles.

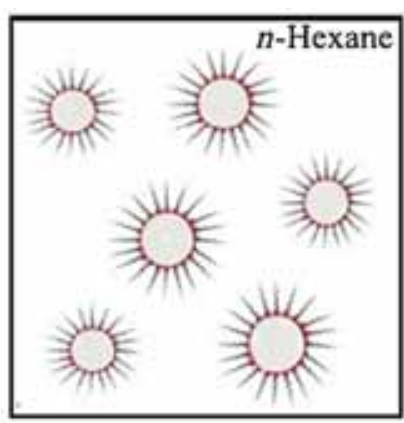

Mic-A: metal nitrates dissolved in aqueous droplets

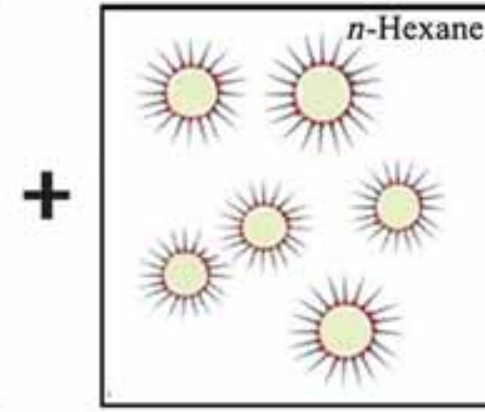

Mic-B: precipitating agent dissolved in aqueous droplets

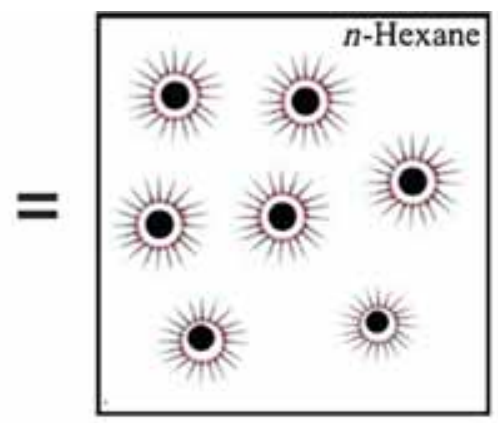

Perovskite precursors form in limited size of aqueous droplets

Figure 1. Schematic representation of precursor formation in water-in-oil microemulsion method. 
A very small weight loss was detected in the range of 400$650^{\circ} \mathrm{C}$. No weight loss appeared thereafter which confirms the formation of perovskite structure. Therefore, it was decided to calcine LSMTO precursor at $700^{\circ} \mathrm{C}$.

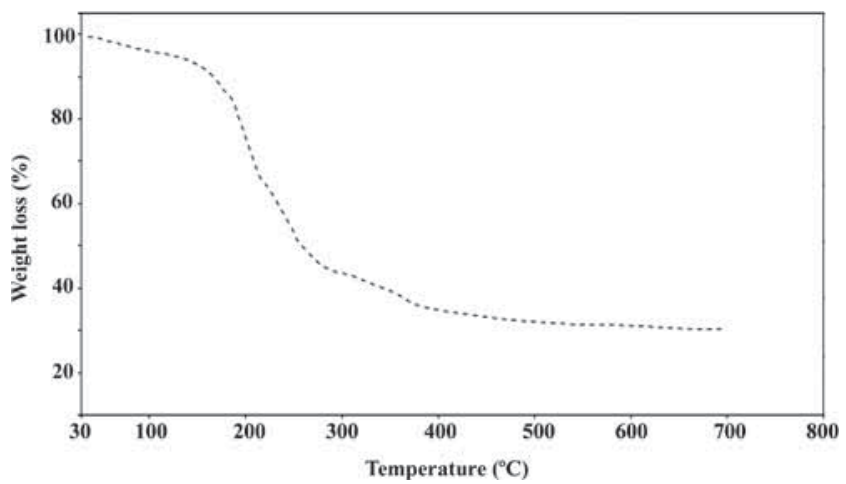

Figure 2. Thermogeravimitry analysis of LSMTO precursor obtained by reverse microemulsion method.

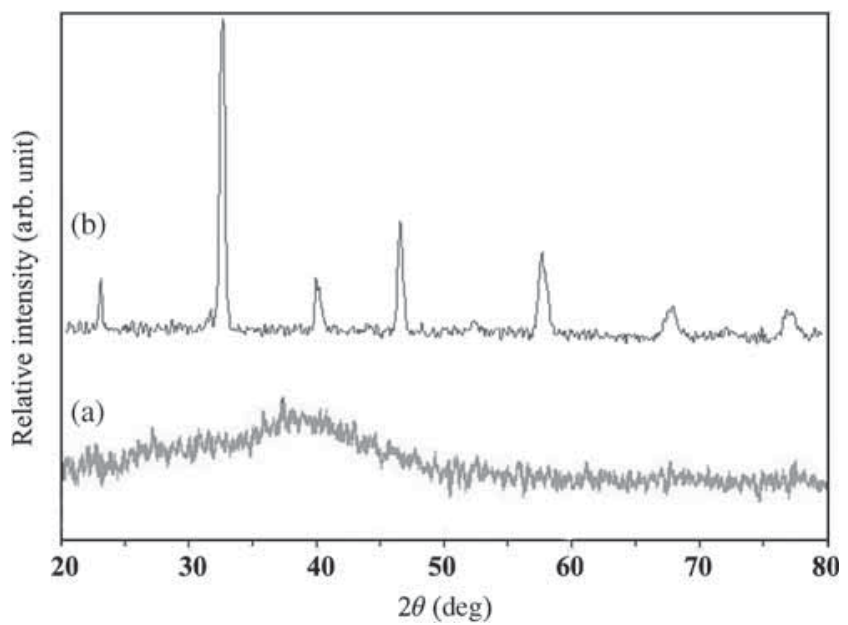

Figure 3. XRD patterns of (a) precursor and (b) LSMTO nanoparticles.

\subsection{X-ray diffraction}

Figure 3 shows the crystalline structure of obtained precursor (curve a) and LSMTO nanoparticles synthesized at $700^{\circ} \mathrm{C}$ (curve b). As it can be seen in curve a the obtained precursor have amorphous structure. In curve $b$, the observed diffraction peaks are corresponded to the perovskite structure of LSMTO nanoparticles $[9,18]$. No peak of any unreacted or impurity phase was detected in the curve b, which indicates the high purity of the obtained product. Also, the average crystallite size ( $D_{\mathrm{XRD}}$ ) of LSMTO nanoparticles was calculated using the well-known Scherrer's equation:

$$
D=0.9 \lambda / \beta \cos \theta,
$$

where $\lambda$ is the incident X-ray wavelength $\left(\lambda_{\mathrm{Cu}}=1.5443 \AA\right)$, $\theta$ the diffraction angle of the peak corresponding to maximum intensity, and $\beta$ the full-width at half-maximum. The average crystalline size of the nanoparticles was calculated to be $20.1 \mathrm{~nm}$.

\subsection{TEM analysis}

The TEM image and corresponding particle size distribution of LSMTO nanoparticles are shown in figure 4. As can be seen, the LSMTO nanoparticles have an irregular shape with an average particle size of about $23.5 \mathrm{~nm}$. Several authors have been studies the effect of particle size on the durability of nanoparticles in body $[19,20]$. It has been observed that the optimum particle size of nanoparticles for long circulation time in body is in the range of $10-50 \mathrm{~nm}$. Therefore, the prepared sample in this study can be used as a heating agent in magnetic hyperthermia therapy.

\subsection{Induction heating analysis}

The time-dependent temperature curves for aqueous suspension of LSMTO nanoparticles (100 $\mathrm{mg} \mathrm{ml}^{-1}$ ) exposed to

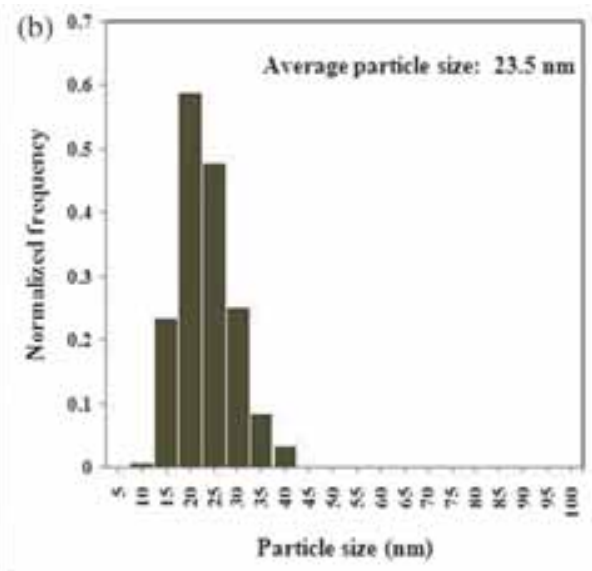

Figure 4. TEM images of (a) LSMTO nanoparticles and (b) particle size distribution nanoparticles. 


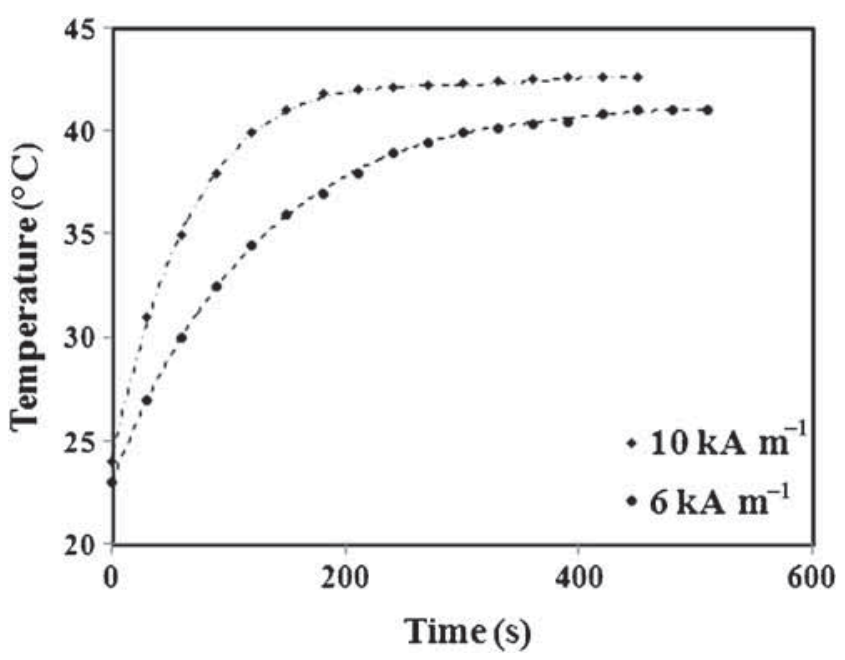

Figure 5. Temperature vs. time for aqueous suspension of LSTMO nanoparticles at different magnetic fields.

an alternating magnetic field with different intensities $(H=$ 6 and $10 \mathrm{kA} \mathrm{m}^{-1}, f=100 \mathrm{kHz}$ ) are shown in figure 5 . As can be seen, when the magnetic fluid was exposed to an AMF, the temperature of the sample was first raised and then stabilized at a certain temperature in the desired temperature range for magnetic hyperthermia therapy. The final temperature of the magnetic fluid is a function of the Curie temperature of the MNPs and also the equilibrium between the heat generated by the nanoparticles and the heat emitted to the environment. In addition, the SAR value of sample was calculated through the initial slope of heating curve $(\mathrm{d} T / \mathrm{d} t)$. The obtained results were 6.0 and $10.8 \mathrm{~W} \mathrm{~g}^{-1}$ for 6 and 10 $\mathrm{kA} \mathrm{m}^{-1}$, respectively, which are comparable with the results obtained by other researchers [21].

\section{Conclusions}

Water-in-oil microemulsion method was employed to prepare $\mathrm{La}_{0.7} \mathrm{Sr}_{0.3} \mathrm{Mn}_{0.98} \mathrm{Ti}_{0.02} \mathrm{O}_{3}$ nanoparticles with $23.3 \mathrm{~nm}$ average particle size. In this method, CTAB was used as the surfactant, 1-butanol as the co-surfactant, $n$-octane as the continuous oil phase and an aqueous solution containing metal cations or precipitating agent as the dispersed phase. The aqueous nanodroplets of microemulsions were used for the formation of perovskite precursor. The obtained precursor was then calcined at $700^{\circ} \mathrm{C}$ for $4 \mathrm{~h}$ to convert precursor to the perovskite phase. The results of calorimetric measurements showed that the heat generation of the prepared sample could be safely controlled in the range of $40-45^{\circ} \mathrm{C}$ which is suitable for magnetic hyperthermia.

\section{References}

[1] Mc Bain S C, Yiu H H and Dobson J 2008 Int. J. Nanomed. 3 169

[2] Soleymani M, Edrissi M and Alizadeh A M 2015 Polym. J. 47 797

[3] Liberti P A, Rao C G and Terstappen L W M M 2001 J. Magn. Magn. Mater. 225301

[4] Zhang M, Jugold E, Woenne T, Lammers B, Morgenstern M M, Mueller H, Zentgraf M, Bock M, Eisenhut W, Semmler and Kiessling F 2007 Cancer Res. 671555

[5] Soleymani M and Edrissi M 2015 Bull. Mater. Sci. 381633

[6] Jordan A, Scholz R, Wust P, Fahling H and Felix R $1999 \mathrm{~J}$. Magn. Magn. Mater. 201413

[7] Gilchrist R K, Medal R, Shorey W D, Hanselman R C, Parrott J C and Taylor C B 1957 Ann. Surg. 146596

[8] Soleymani M and Edrissi M 2016 J. Dispersion Sci. Technol. 37693

[9] Phuc N X, Hieu N T, Le N T H, Manh D H, Tuan N A, Hong L V and Tuong L T C 2008 J. Korean Phys. Soc. 521492

[10] Nam N H, Huong D T M and Luong N H 2014 IEEE Trans. Magn. 501

[11] Zi Z F, Sun Y P, Zhu X B, Yang Z R, Dai J M and Song W H 2009 J. Magn. Magn. Mater. 3212378

[12] Cuong P V, Dho J, Park H Y and Kim D H 2009 Appl. Phys. A 95567

[13] Daengsakul S, Mongkolkachit C, Thomas C, Siri S, Thomas I, Amornkitbamrung V and Maensiri S 2009 Appl. Phys. A 96 691

[14] Sayagues M J, Cordoba J M and Gotor F J 2012 J. Solid State Chem. 18811

[15] Boutonnet M, Kizling J, Stenius P and Maire G 1982 Colloid Surf. 5209

[16] Ahmad T, Ramanujachary K V, Lofland S and Ganguli A 2006 J. Chem. Sci. 118513

[17] Giannakas A E, Ladavos A K and Pomonis P J 2004 Catalysis B: Environmental 49147

[18] Sayagues M J, Cordoba J M and Gotor F J 2012 J. Solid State Chem. 18811

[19] Tabata Y and Ikada Y 1990 Adv. Polym. Sci. 94107

[20] Choi H S, Liu W, Misra P, Tanaka E, Zimmer J P, Ipe B I, Bawendi M G and Frangioni J V 2007 Nat. Biotechnol. 25 1165

[21] Kuznetsov A A, Shlyakhtin O A, Brusentsov N A and Kuznetsov O A 2002 Eur. Cells Mater. 375 